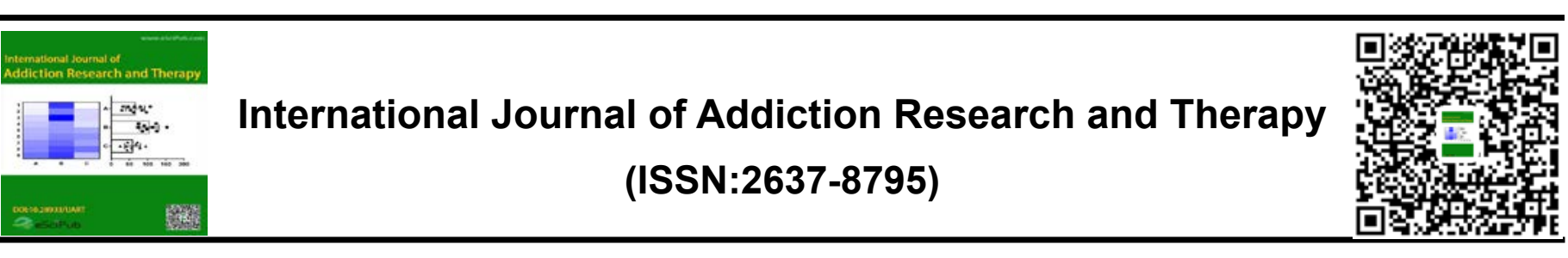

\title{
IMPULSIVITY IN COCAINE/CRACK USERS IN THE CITY OF ARAPIRACA IN ALAGOAS
}

\author{
Ademir Ferreira Júnior1*, Lino José da Silva1, Maria Sandinéia Bezerra1, Taciana Silva Dias \\ Nogueira1, Ana Caroline Melo dos Santos2, Virginia Elaine Martins de Souza Figueiredo.
}

\section{ABSTRACT}

Introduction: Currently drug use is as a major problem of global public health, given the diversity of aspects involved in drug abuse, psychoactive substances exert impacts on users, families and community, contributing to damage to the physical and mental health, as well as the socio-economic vulnerability and legal problems. Objective: Analyze the degree of cocaine / crack users behavior in Cozy Communities and the Reference Center for Population Homeless (POP Center) located in Arapiraca city in Alagoas. Methodology: This is a research with a quantitative approach, performed in Cozy Communities and POP Center, which are distributed in the city of Arapiraca. The instrument used for the production of data was made by means of structured interviews conducted in the period May to July 2018, in its physical space of the institutions, listing the sociodemographic profile and Impulsiveness Scale - BIS 11. For impulsive behavior grade analysis was used to impulsiveness scale - 11 BIS, based on "Ernst Barratt model, which is considered as one of the most important in impulsive behavior explanation". Results: The results obtained, the overall score obtained an average of 2.38 were found for each partial average score of the three subdomains impulsiveness, the resulting average motor impulsivity: 2.24 to attentional impulsivity: 2.51 and impulsivity not planning: 2.34. Conclusion: This study shows the importance of impulsivity associated with the pattern of use of psychoactive substances.

Keywords: Cocaine/crack, behavior, nursing.
${ }^{*}$ Correspondence to Author:

Ademir Ferreira Júnior

How to cite this article:

Ademir Ferreira Júnior, Lino José da Silva, Maria Sandinéia Bezerra, Taciana Silva Dias Nogueira, Ana Caroline Melo dos Santos, Virginia Elaine Martins de Souza Figueiredo. IMPULSIVITY IN COCAINE/ CRACK USERS IN THE CITY OF ARAPIRACA IN ALAGOAS.International Journal of Addiction Research and Therapy, 2019, 2:7

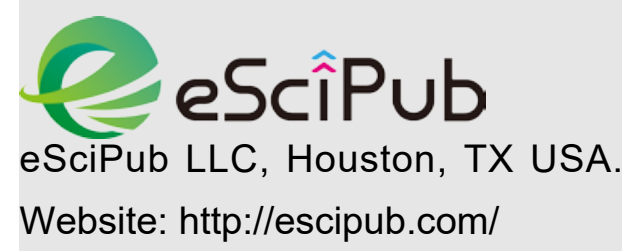




\section{INTRODUCTION}

Before the Fiocruz study commissioned by the National Policy on Drugs, crack consumption and the like in the Brazilian capital, the indirect household survey carried out in 2012, it is estimated that there are in this year's survey, about 370,000 regular users (over 25 days of use in the past 6 months) would represent $0.81 \%$ of the total population residing in these districts. Within this number, 370,000 crack users and their counterparts in the Brazilian capital, the northeast region emerges with the largest number of users, 148 thousand about $38.7 \%$, the macro-northeast is just behind the Southeast with 113000 or $29.6 \%$ of drug users in this region ${ }^{1}$.

To think in broader form of drugs, it is characterized as any substance not produced in the body with property changes of mental functions. Be changes in mood, behavior, judgment, perception etc ${ }^{2}$. But in particular, the use of cocaine / crack carries features that clash with its effects on many other drugs, for its high potential for addiction because of the intense craving by stimulating the repetitive and overuse, leaving the user in risky behavior intended the search of the drug, causing social and personal impacts ${ }^{3}$. Therefore the levels of crime and violence by drug addicts, are generally associated with the use of crack and its consequences ${ }^{4}$.

Currently drug use is as a major problem of global public health, given the diversity of aspects involved in drug abuse, psychoactive substances exert impacts on users, families and community, contributing to damage to the physical and mental health, as also the socioeconomic vulnerability and legal problems. The addict is affected by the type of drug and nature of violent behavior, compromising their interaction with the world 5 .

Impulsivity becomes one of the aspects of personality for expressions of violent behavior, it is characterized as a self-inability of the individual, who does not control his actions and behavior, acting unthinkingly, without measuring the consequences, and this refers to various spheres of your life (personal, social, professional) and may be associated with mental health problems, substance use, problems in relationships and manifestations of acts violents ${ }^{5}$.

Although studies show that the impulsivity is positively associated with violence ${ }^{6}$, not postulate that there is a causal relationship in dependence on cocaine / crack next to impulsivity factors and violence, we believe that in addition to the use of these psychoactive substances, there are also factors such as life history, culture, personality, occupational perspectives that also influence impulsiveness and violent behavior?

There is a complexity to study the relationship between drug use and impulsivity, with respect to the field of violence in the consumption of psychoactive substances such problematic inserted in modern society have plagued families, local, national and international communities, forcing authorities and researchers to give effective responses to such demand $^{8}$.

\section{OBJECTIVE}

Analyze the degree of impulsive behavior from the Impulsiveness Scale - BIS 11, based on Ernst Barratt model of cocaine/crack users in Cozy Communities and the Reference Center for Population Homeless (POP Center) located in the municipality Arapiraca in Alagoas.

\section{METHODS}

This summary refers to a study based on extension project actions: "Health Interventions Of Cocaine Users / Crack In Cozy Communities; Promoting Community Circles ". This is a research with a quantitative approach, performed in Cozy Communities and Specialized Reference Center for Population Homeless (POP Center) which are distributed in the city of Arapiraca, namely Casa Dona Paula, Home Sow and Center Reference for Population Homeless (POP Center), which have as main objectives the rehabilitation and 
reintegration of drug addicts. The summary used 25 users for samples, welcomed in institutions. The instrument used for the production of data was made by means of structured interviews conducted in the period May to July 2018.

For the analysis of the degree impulsive behavior was used Impulsiveness Scale - 11 BIS, based on "Ernst Barratt model, which is considered one of the most important in impulsive behavior explanation"9. The manifestations of impulsivity are arranged in 30 items that are answered according to the categorization, as follows: 1 = rarely or never; 2 = Occasionally; 3 = frequently; 4 = almost always / always. The score of the scale ranges from 30 to 120 points, and high scores indicate the presence of impulsive behaviors. In addition an overall score, BIS-11 allows the calculation of partial scores relating to three subdomains impulsivity, namely motor impulsivity (Items 2 , $\left.3,4,16,17,19,21,22,23,25,30^{*}\right)$, attentional (items $6,5,9 *, 11,20 *, 24,26,28$ ) and non planning (items $1^{*}, 7^{*}, 8^{*}, 10^{*}, 12^{*}, 13^{*} 14$, $15 *, 18,27,29 *)$. Items marked with * receive the signal inverse score for the calculation of partial and full score $(4,3,2,1)^{10}$.

The inclusion criteria for sample participation, were the participants have a history of cocaine / crack in the last 12 months and who wished to participate. The exclusion criteria, were excluded users who used cocaine / crack for over 12 months and users who were using substances that do not match the purpose of the study. Data analysis was performed using descriptive statistics in Microsoft Excel, version in 2010. The questions were separated according to the scale of impulsiveness subdomains BIS 11. In the partial results for each question, added to all response participants, obtaining therefore its average. The average of each sub-domain was obtained by calculating the average of the questions for each subdomain.

All research bolstered by the ethical conduct, and the research project approved by the
Research Ethics Committeeand the Federal University of Alagoas (UFAL) under CAAE No 67643417.3.0000.5013. For participants, the Term of Informed Consent Form (ICF) was introduced, it was arranged in two copies, one copy to the participant and the other held by the researcher. The IC features options including the choice whether or not you need a new consent every future research or waiver of this.

\section{RESULTS}

The study of the impulsive behavior had a sample of 25 subjects, 24 of these $(92 \%)$ were male and $02(8 \%)$ women. The average age of the population 32.4 (SD 10.3), with a minimum of 18 and maximum of 55 years. Considering the institution that welcomes drug users to treatment11 (44\%) belong to the subject POP center and $14(56 \%)$ subjects in host communities. With respect to location area 21 $(84 \%)$ participants are in the urban area, and only $4(16 \%)$ reside in rural areas.

The results obtained, the overall score obtained an average of 2.38 were found for each partial average score of the three subdomains impulsiveness, the resulting average motor impulsivity: 2.24 to attentional impulsivity: 2.51 and impulsivity not planning: 2.34 .

According to the profile of the participants, we note that all are multiple drug users where cocaine / crack is their drug of choice. The association of multiple psychoactive substances is associated with higher scores impulsivity ${ }^{11}$. The impulsive behavior of the user of the drug effect can be explained by the association between the use of crack and criminality ${ }^{12}$.

All participants are users of cocaine / crack and make or have made use of other psychoactive substance, and marijuana (92\%), alcohol $(88 \%)$, inhalants $(48 \%)$, benzodiazepines and inhalants (both 24\%), amphetamine and opioids (both $4 \%$ ), whereas all participants are users multiple drugs.

American studies dealing impulsiveness in marijuana users, psychoactive substance used 
by $92 \%$ of the sample, relates to the amount of drug used per month and targeted interventions impulsivity are necessary to reduce the problematic use this drug $^{13}$. As for users of alcohol, corresponding to $88 \%$ of the participants, impulsiveness is also related to the amount of drug used, and factors such as age who initiated the use, frequency and excessive consumption ${ }^{14}$.

No studies were found involving the pattern of drug use with impulsivity.

Table 1 - drug use patterns.

\begin{tabular}{|c|c|}
\hline Variables & $N=25(100 \%)$ \\
\hline Use multidrug & $25(100)$ \\
\hline \multicolumn{2}{|l|}{ Drug that has already made use } \\
\hline Cocaine / crack & $25(100)$ \\
\hline Marijuana & $23(92)$ \\
\hline Alcohol & $22(88)$ \\
\hline Inhalant & $12(48)$ \\
\hline benzodiazepine & $6(24)$ \\
\hline LSD & $6(24)$ \\
\hline Amphetamine & $1(4)$ \\
\hline Opioid & $1(4)$ \\
\hline \multicolumn{2}{|l|}{ Forms of use of cocaine / crack } \\
\hline Smoked crack mixed with marijuana & $15(60)$ \\
\hline Smoked crack with pipe & $13(52)$ \\
\hline Crack smoked tobacco & $12(48)$ \\
\hline Smoked crack on soft drinks / beer can & $8(32)$ \\
\hline Crack smoked plastic cup & $2(8)$ \\
\hline Cocaine / crack associated with alcohol & $2(8)$ \\
\hline Cocaine suctioned & $2(8)$ \\
\hline
\end{tabular}

Source: Author, 2018.

\section{CONCLUSION}

The present study shows the importance of impulsivity associated with the pattern of use of psychoactive substances. In addition to the level of dependency, these substances have a direct influence on impulsive behavior and can lead those users crime.

\section{REFERENCES}

1. Bastos FI Bertoni C (Org.). National research on the use of crack: who are the users of crack and / or the like in Brazil? how many are in the state capitals? Ed: ICICT / FIOCRUZ - Rio de Janeiro, 2014.

2. Cruz, MS Strategies harm reduction for people with drug problems at the interface of the operating fields of justice and health. In Andrade AG. 2011.

3. TV keys, Sanchez ZM, Ribeiro LA, Nappo SA. Crack cocaine craving: behavior and user and former user control strategies. Rev Health Governm. 2011.
4. Orange R, Duailibi SM, I. Pinsky Alcohol and violence: psychiatry and public health. Rev Bras Psiquiatr. 2005.

5. Sharma L, Markon KE, Clark, L A. Toward a theory of distinct types of "impulsive" behaviors: A meta-analysis of self-report and behavioral measures: American Psychological Association. 2014.

6. PC Morais. Drugs: criminalization and alternative Brazilian legislative trend [Monographs on the Internet]. Minas Gerais: Crime Studies Center and Public Safety; 2005.

7. LG Barbosa, R. Vidal MC, Tambellini, AT A sitting posture and human motor function in the context of school children: the backpack is not solely responsible for postural problems. Ed: Fisioter. Bras, 2006.

8. Santoucy LB, MI Conception, Sudbrack MF. Understanding the right of operators of the Federal District on drug user in the enactment of the new law. Ed: Psicol Re fl ex Crit. 2010.

9. Fernandes R. impulsivity scale validation studies BIS Barratt 11 for a sample of the Portuguese 
population. Thesis (Ph.D.) - Course of Psychology, University of Coimbra - Faculty of Psychology and Educational Sciences, Coimbra, 2014.

10. Malloy-Diniz Leandro Fernandes, Paulo Mattos, Milk Wellington Borges, Abreu Neander, Gabriel Coutinho, Paula Jonas Garden et al. Translation and cultural adaptation of the Barratt Impulsiveness Scale (BIS-11) for application to Brazilian adults. J. bras. psiquiatr. [Internet]. 2010 [cited 2018 Oct 15]; 59 (2): 99-105.

11. OM Michael Ernest SB. Impulsivity and DSMIII$\mathrm{R}$ personality disorders. Personality and Individual Differences 1993; 14, 609-611.
12. Cristiane CLB, Jaqueline SAM. Violent behavior among crack users. Avances en Enfermería 2015 ten: 33.1: 75-84.

13. Rachel Luba, Mitch Earleywine, Stacey Farmer, Melissa Slavin, Maha Mian \& Brianna Altman. The role of impulsivity and expectations Anticipating Marijuana Use: An application of the Acquired preparation model. Journal of Psychoactive Drugs 2018.

14. Maurizio Coppola, Raffaella Mondola.Impulsivity in Alcohol-Dependent Patients with and without ADHD: The Role of Atomoxetine, Journal of Psychoactive Drugs 2018.

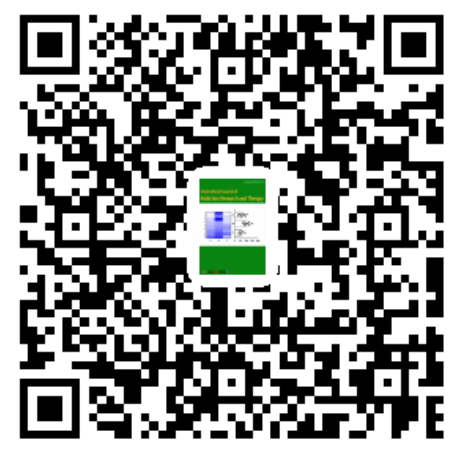

